\title{
Anxiety, depression and perceived stress among breast cancer patients: single institute experience
}

\author{
H. A. Alagizy ${ }^{1}$, M. R. Soltan², S. S. Soliman ${ }^{3}$, N. N. Hegazy ${ }^{4}$ and S. F. Gohar ${ }^{1}$
}

\begin{abstract}
Background: Statistics reveal that the number of women diagnosed with breast cancer is increasing in Egypt. It is seen as a terrifying disease due to its high mortality rate and its impacts on the self-image and the sexual relationship. Many of its patients experience psychological reactions and may have psychiatric morbidities. The present study aimed to identify the prevalence and associated psychosocial factors of anxiety, depressive disorders, and perceived stress among breast cancer patients in Menoufia university hospitals. This cross-sectional study was conducted in the Clinical Oncology Department, Menoufia University. Sixty patients were subjected to questionnaires for socio-demographic data, structured psychiatric clinical interview to screen for psychiatric diagnoses, Beck Depression Inventory (BDI-II) for measuring the emotional, cognitive and motivational symptoms of depression, Manifest Anxiety Scale to assess the degree of anxiety, and Perceived Stress Scale (PSS-10) to assess stress level.

Results: The prevalence of depressive symptoms, anxiety symptoms, and perceived stress were $68.6 \%, 73.3 \%$, and $78.1 \%$ respectively. Moderate to severe anxiety, depression, and stress were more prevalent among advanced disease patients, patients who underwent surgery, married patients, patients who were living in rural areas, illiterate, and those without satisfactory income but without statistically significant difference except for the effect of occupation on the anxiety state as unemployed patients had significantly higher prevalence of moderate to severe anxiety (100\%) than employed patients $p=0.003$.

Conclusion: Depressive disorders, anxiety, and perceived stress are common psychiatric disorders among the studied breast cancer patients. Understanding these common psychiatric disorders and associated stress can help to plan for their management.
\end{abstract}

Keywords: Depression, Anxiety, Perceived stress, Breast cancer

\section{Background}

Breast cancer is the most frequently diagnosed cancer and the leading cause of cancer deaths among females worldwide and the second most common cancer overall [1].

Studies have shown that prevalence of psychological distress among breast cancer patients is high, and they are at higher risk of developing severe anxiety and depression [2,3]. Cancer may induce the development of

\footnotetext{
* Correspondence: Dr.mohamedsoltan1979@gmail.com

${ }^{2}$ Department of Psychiatry, Faculty of Medicine, Fayoum University, PO Box 63514, Fayoum, Egypt

Full list of author information is available at the end of the article
}

psychiatric disorders especially among women whom having breast cancer and these effects can be on both the patients and their family members [4]. Depression and anxiety are the two most common psychiatric comorbidities present among breast cancer patients $[5,6]$.

Recently, more attention has been paid to the rapidly increasing prevalence of psychiatric problems happening in breast cancer patients. As well known, diagnosis and treatment of breast cancer cases can be a very stressful issue during and after the treatment [7]. It is very important to take early measures to treat these psychosocial problems

\section{Springer Open}

(c) The Author(s). 2020 Open Access This article is licensed under a Creative Commons Attribution 4.0 International License, which permits use, sharing, adaptation, distribution and reproduction in any medium or format, as long as you give appropriate credit to the original author(s) and the source, provide a link to the Creative Commons licence, and indicate if changes were made. The images or other third party material in this article are included in the article's Creative Commons licence, unless indicated otherwise in a credit line to the material. If material is not included in the article's Creative Commons licence and your intended use is not permitted by statutory regulation or exceeds the permitted use, you will need to obtain permission directly from the copyright holder. To view a copy of this licence, visit http://creativecommons.org/licenses/by/4.0/. 
for breast cancer patients and their partners thus improving their quality of life [4].

The present study aimed to identify the prevalence and associated psychosocial factors of anxiety, depressive disorders, and perceived stress among sample of breast cancer patients.

\section{Methods}

This is a cross-sectional, analytical study conducted in the Clinical Oncology Department in Menoufia University, which serves urban and rural areas and provides health care services to different social classes.

\section{Subjects}

All cases were recruited during a 6-month interval starting from January 2019 to July 2019. All cancer breast female patients attending outpatient clinic (either in postoperative stage or presented with advanced metastatic disease), waiting for the further decision in the treatment plan whether chemotherapy or radiotherapy, were invited to participate in the study. Finally, the study included 64 Egyptian female patients. In order to control for the confounding effects of prior medical or neurological illnesses, the following exclusion criteria were adopted for all cases: patients having any disorder that clearly interferes with cognition, such as central nervous system lesions, severe hepatic, or renal dysfunction; patients having severe organ failure (hepatic, renal, cardiac); patients who received previous chemotherapy or radiotherapy or had recurrent disease; patients who had poor performance status (2 or more) based on ECOG performance status scale [8] or had personal history of other types of cancers; and patients who had past history of any psychiatric disorders.

All the participants were screened to determine eligibility for participation in the study. Screening was conducted through an interview form, which inquired about demographic data, cancer breast history, and medical history information. Based on their response, subjects were approved to continue participation in this study.

\section{Methods}

All the patients were subjected to the following: questionnaire for socio-demographic data: (1) personal data including age, marital status, education, occupation, residency, and history of breast cancer and (2) disease data: stages and type of operations that had been done.

The disease staging was based on TNM staging system and the patients were categorized into patients with early stage (stages I and II) and patients with advanced stage (stages III and IV) disease.

The patients were subjected to clinical psychiatric assessment using Structured Clinical Interview for DSMIV (SCID I) Arabic version [9] that used to diagnose an axis I psychiatric diagnosis. It is a semi-structured diagnostic interview which has been updated for DSM-5. It is considered the standard interview to verify diagnosis in clinical trials and is extensively used in other forms of psychiatric research.

A self-report rating scale, Beck Depression Inventory (BDI-II-Arabic version) [10], translated to Arabic by Gharib Abdel Fattahin [11], was used for measuring the emotional, cognitive, and motivational symptoms of depression. The original scale consists of 21 items, each containing four alternatives, scored from 0 to 3 . The total scores range from 0 to 63 . Higher scores in the scale indicate the greater severity of depression. Scoring of Beck's inventory: mild depression: (14-19), moderate depression: (20-28), and severe depression: (29-63).

The Manifest Anxiety Scale [12] was performed to assess the anxiety state. This early instrument is derived from the MMPI in which the patient has to answer yes or no to these questions, which are phrased in formal Arabic and can be understood by all those people who can read simple Arabic. Scoring: the total score indicates the severity of the anxiety state, score from 0 to 16 is considered normal, from 17 to 25 indicates mild anxiety, from 25 to 36 indicates moderate anxiety, while scores above 36 indicate severe anxiety. The scale which has been validated and translated into Arabic by AbdelKhalek [13] was used in this study.

The Perceived Stress Scale (PSS-10) [14] which was validated and translated into Arabic by Chaaya et al. [15] was used to assess stress level. The Arabic version of PSS-10 was found to have adequate reliability and validity. The PSS-10 covers two factors. The first factor included questions reflecting negative feelings (being upset, angry, or nervous) and inability to handle stress, while the second factor included questions expressing positive emotions and ability to act in stressful situations. The 10 items in the scale inquire about feelings and thoughts that tap the degree to which respondents find their current life situation unpredictable, uncontrollable, and stressful. Respondents indicate how often in the past month they have felt or thought a certain way on a 5 -point Likert scale $(0=$ never, $1=$ almost never, 2 = sometimes, $3=$ fairly often, $4=$ very often). The higher the score, the higher the perceived stress is. The scale correlates with different psychosocial measures specifically depression and perception of poor health.

\section{Statistical analysis}

Results were analyzed by SPSS statistical package version 23 [16].

Student's $t$ test is a test of significance used for comparison of quantitative variables between two groups of normally distributed data, while Mann Whitney's test 
Table 1 Patients' and disease characteristics $(n=64)$

\begin{tabular}{|c|c|}
\hline Variable & Mean $\pm S D$, range \\
\hline Age & $52.29 \pm 11.64,30.0-75.0$ \\
\hline Family members & $5 \pm 2,1-13$ \\
\hline Number of children & $4 \pm 2,0-11$ \\
\hline Variable & No. (\%) \\
\hline \multicolumn{2}{|l|}{ Marital status } \\
\hline Never married & $4(6.3)$ \\
\hline Married & $47(73.4)$ \\
\hline Widow & $13(20.3)$ \\
\hline \multicolumn{2}{|l|}{ Residence } \\
\hline Rural & $14(21.9)$ \\
\hline Urban & $50(78.1)$ \\
\hline \multicolumn{2}{|l|}{ Education of the patients } \\
\hline Illiterate & $32(50.0)$ \\
\hline Secondary & $29(45.3)$ \\
\hline Higher & $3(4.7)$ \\
\hline \multicolumn{2}{|c|}{ Education of the husband } \\
\hline Illiterate & $26(40.6)$ \\
\hline Secondary & $33(51.6)$ \\
\hline Higher & $5(7.8)$ \\
\hline \multicolumn{2}{|l|}{ Occupation } \\
\hline Housewife $(n=61)$ & $61(95.3)$ \\
\hline Working $(n=3)$ & $3(4.7)$ \\
\hline \multicolumn{2}{|c|}{ Occupation of the husband } \\
\hline Manual worker & $43(67.2)$ \\
\hline Employee & $12(18.8)$ \\
\hline Retired & $9(14.0)$ \\
\hline \multicolumn{2}{|l|}{ Income } \\
\hline Enough & $17(26.6)$ \\
\hline Not enough & $47(73.4)$ \\
\hline \multicolumn{2}{|l|}{ Medical comorbidity } \\
\hline Present & $18(28.1)$ \\
\hline Absent & $46(71.9)$ \\
\hline \multicolumn{2}{|l|}{ Menopausal } \\
\hline Premenopausal & $36(56.3)$ \\
\hline Postmenopausal & $28(43.8)$ \\
\hline \multicolumn{2}{|c|}{ Family history psychiatric disorder } \\
\hline Yes & $6(9.4)$ \\
\hline No & $58(90.6)$ \\
\hline Disease characteristics & No. (\%) \\
\hline \multicolumn{2}{|l|}{ Stage } \\
\hline । & $5(7.8)$ \\
\hline$\|$ & $16(25.0)$ \\
\hline III & $32(50.0)$ \\
\hline IV & $11(17.2)$ \\
\hline
\end{tabular}

Table 1 Patients' and disease characteristics $(n=64)$

(Continued)

\begin{tabular}{ll}
\hline Variable & Mean \pm SD, range \\
\hline Surgery & \\
MRM & $46(71.9)$ \\
CS & $7(10.9)$ \\
No surgery & $11(17.2)$ \\
\hline
\end{tabular}

was used for comparison of quantitative variables between two groups of not normally distributed data.

Chi-squared test $\left(\chi^{2}\right)$ was used to study association between qualitative variables. Whenever any of the expected cells were less than five, Fischer's exact test was used.

ANOVA test was used for comparison of quantitative variables between more than two groups of normally distributed data; Kruskal-Wallis test was used for comparison of quantitative variables between more than two groups of not normal distributed data. Univariate logistic regression model was performed to ascertain the effect of each risk factor on the intended outcome. $p$ value < 0.05 was considered significant.

\section{Results}

Sixty four female patients in the present study had good performance status $(0-1)$. The mean age of the studied group was $52.29 \pm 11.64$ years old. The mean number of their family members was $5 \pm 2$ subjects. Only 4 patients (6.3\%) were not married, 47 (73.4\%) were married, and $13(20.3 \%)$ were widows. Half of patients were (32 patient) illiterate. Most of the participants, 61 cases (95.3\%) were housewives, and only $3(4.7 \%)$ were working. Seventeen (26.6\%) women reported that they have enough income and $47(73.4 \%)$ reported they have not. Medical comorbidities were found in 18 women (28.1\%), while 46 (71.9\%) did not have any medical comorbidity. Nearly half of the women (56.3\%) were still in their premenopausal state and $9.4 \%$ had family history of psychiatric disorders (Table 1).

Half of the participating women had stage III breast cancer. According to the pathological grading, they were distributed as $5(7.8 \%)$ in stage I, $16(25.0 \%)$ in stage II, $32(50 \%)$ in stage III, and $11(17.2 \%)$ in stage IV. More than two-thirds of the included women (71.9\%) had undergone modified radical mastectomy (MRM), 7 (10.9\%) of them had conservative surgery (CS), while 11 women $(17.2 \%)$ did not have any breast surgery till the time of this study (Table 1).

The prevalence of depressive symptoms in the study group was $68.7 \%$. The overall mean score of Beck Depression Inventory (BDI-II) was $16.56 \pm 13.31$. Twenty women had no depressive symptoms (31.3\%), 12 (18.8\%) had mild, 18 (28.1\%) had moderate, 12 (18.8\%) had 
severe, while only 2 women (3.1\%) had very severe depressive symptoms (Table 2 ).

The prevalence of anxiety symptoms in the study group was $73.3 \%$. The mean score of Taylor anxiety scale was $22.81 \pm 11.10$. Seventeen women $(26.6 \%)$ had very low anxiety symptoms, 5 (7.8\%) had low, 15 (23.4\%) had high, 6 (9.4\%) had above moderate, 14 women (21.9\%) had severe anxiety symptoms, and 7 women (10.9\%) had very severe anxiety symptoms. The prevalence of combined anxiety-depression was present in $31.25 \%$ of cases (20 patients) (Table 2 ).

The prevalence of stress in the study group was $78.1 \%$. The mean score of Perceived Stress Scale (PSS) was $17.89 \pm 7.55$. Fourteen women $(21.9 \%)$ had low stress level, 44 (68.8\%) had moderate, and 6 women (9.4\%) had high stress level (Table 2).

Regarding the relationship between the expected risk factors and the psychiatric disorders, there was no significant association between the expected risk factors and the psychiatric disorders among cancer breast patients except the effect of occupation on the anxiety state (Tables 3, 4, and 5) as:

About half $(31.8 \%)$ of early disease patients (stages I and II) had moderate to severe depression, $26.2 \%$ moderate to severe anxiety, and $36 \%$ moderate to severe stress, while $68.2 \%$ of advanced disease patients (stage III and IV) had moderate to severe depression,73.8\%

Table 2 Distribution of psychiatric diagnoses in the cases regarding psychiatric assessment scales $(n=64)$

\begin{tabular}{ll}
\hline Diagnosis & No. (\%) \\
\hline Depression & $20(31.3)$ \\
No depression & $12(18.8)$ \\
Mild & $18(28.1)$ \\
Moderate & $12(18.8)$ \\
Severe & $2(3.1)$ \\
Very severe & \\
Anxiety & $17(26.6)$ \\
Very low & $5(7.8)$ \\
Low & $6(9.4)$ \\
Above moderate & $15(23.4)$ \\
High & $14(21.9)$ \\
Severe & $7(10.9)$ \\
Very severe & $20(31.25)$ \\
Mixed anxiety depression & \\
Perceived stress & $14(21.9)$ \\
Low stress & $44(68.8)$ \\
Moderate stress & $6(9.4)$ \\
High stress &
\end{tabular}

moderate to severe anxiety, and $64 \%$ moderate to severe stress.

Fifty percent $(81.8 \%)$ of the patients who underwent surgery had moderate to severe depression, $81 \%$ moderate to severe anxiety, and $81.1 \%$ moderate to severe stress, while $18.2 \%$ of the patients who did not underwent surgery had moderate to severe depression, $19 \%$ moderate to severe anxiety, and 14\% moderate to severe stress.

Married patients had higher prevalence of moderate to severe depression (71.4\%) than single females (20.5\%) (never married, divorced, and widow), and about $60 \%$ of the married patients had moderate to severe anxiety, $74 \%$ moderate to severe stress, while $28.6 \%$ of the single females had moderate to severe anxiety and $26 \%$ moderate to severe stress but without significance difference between them.

Fifty four percent (54\%) of the pre-menopausal patients had moderate to severe depression, $50 \%$ moderate to severe anxiety, and $54 \%$ moderate to severe stress, while a little more than half (45\%) of the postmenopausal patients had moderate to severe depression, $50 \%$ moderate to severe anxiety, and $46 \%$ moderate to severe stress.

Among patients who were living in rural areas, $77.3 \%$ had moderate to severe depression, $81 \%$ moderate to severe anxiety, and $80 \%$ moderate to severe stress, while $22.7 \%$ of patients who are living in urban areas had moderate to severe depression, $19 \%$ moderate to severe anxiety, and $20 \%$ moderate to severe stress.

Meanwhile, not working or unemployed patients had significantly higher prevalence of moderate to severe anxiety (100\%) than employed females $(0 \%) p=0.003$. Nearly ninety-eight $(97.7 \%)$ of the not working or unemployed patients had moderate to severe depression and $96 \%$ moderate to severe stress, while $2.3 \%$ of the employed females had moderate to severe anxiety and $4 \%$ moderate to severe stress but without significance difference between them.

Nearly $43 \%$ of the illiterate patients had moderate to severe depression, $45.2 \%$ moderate to severe anxiety, and $50 \%$ moderate to severe stress, while $56.8 \%$ of educated patients had moderate to severe depression, $54.8 \%$ moderate to severe anxiety, and 50\% moderate to severe stress.

Lastly, nearly $68 \%$ of the patients who had not satisfactory income had moderate to severe depression, $85.1 \%$ moderate to severe anxiety, and $95.7 \%$ moderate to severe stress, while $52.9 \%$ patients who had satisfactory income had moderate to severe depression, $29.4 \%$ moderate to severe anxiety, and $29.4 \%$ moderate to severe stress.

Spearman correlation analysis did not show any significant correlation between the stress level measured by PSS and depression scale score $(r 0.22, p 0.07)$ or anxiety scale score $(r 0.09, p 0.47)$. 
Table 3 Relationship between the total number of cases and patients with depression as regarding patient's and disease's characteristics

\begin{tabular}{|c|c|c|c|c|}
\hline & $\begin{array}{l}\text { Total }(\boldsymbol{n}=64) \text {, } \\
\text { no. }(\%)\end{array}$ & $\begin{array}{l}\text { Depression }(\boldsymbol{n}= \\
44) \text { no. }(\%)\end{array}$ & $\begin{array}{l}\text { Test of } \\
\text { significance }\end{array}$ & $\begin{array}{l}\boldsymbol{p} \\
\text { value }\end{array}$ \\
\hline \multicolumn{5}{|l|}{ Stage } \\
\hline Early & $21(32.8)$ & 14 (31.8) & $x^{2}=0.06$ & 0.80 \\
\hline Advanced & $43(67.2)$ & $30(68.2)$ & & \\
\hline \multicolumn{5}{|l|}{ Surgery } \\
\hline $\begin{array}{l}\text { Done (MRM, } \\
\text { CS) }\end{array}$ & 53 (82.8) & $36(81.8)$ & $F E=0.09$ & 1.00 \\
\hline Not & $11(17.2)$ & $8(18.2)$ & & \\
\hline \multicolumn{5}{|l|}{ Marital status } \\
\hline Single & $17(26.5)$ & $9(20.5)$ & $x^{2}=2.69$ & 0.10 \\
\hline Married & $47(73.4)$ & $35(79.5)$ & & \\
\hline \multicolumn{5}{|l|}{ Menopause } \\
\hline Pre & $36(56.3)$ & $24(54.5)$ & $x^{2}=0.16$ & 0.68 \\
\hline Post & $28(43.8)$ & $20(45.5)$ & & \\
\hline \multicolumn{5}{|l|}{ Residence } \\
\hline Urban & $14(21.9)$ & $10(22.7)$ & $F E=0.06$ & 1.00 \\
\hline Rural & $50(78.0$ & $34(77.3)$ & & \\
\hline \multicolumn{5}{|l|}{ Occupation } \\
\hline Unemployed & 61 (95.3) & $43(97.7)$ & $\mathrm{FE}=1.83$ & 0.17 \\
\hline Employee & $3(4.7)$ & $1(2.3)$ & & \\
\hline \multicolumn{5}{|l|}{ Education } \\
\hline Illiterate & 33 (51.6) & $19(43.2)$ & $x^{2}=1.55$ & 0.21 \\
\hline Educated & $31(48.4)$ & $25(56.8)$ & & \\
\hline \multicolumn{5}{|l|}{ Income } \\
\hline Satisfactory & $17(26.6)$ & $9(52.9)$ & $x^{2}=3.35$ & 0.06 \\
\hline $\begin{array}{l}\text { Not } \\
\text { satisfactory }\end{array}$ & $47(73.4)$ & $36(67.5)$ & & \\
\hline
\end{tabular}

The univariate regression analysis model did not show any significance association between the risk factors and any of depression, anxiety, or stress (Table 6).

\section{Discussion}

Despite improvements in the early detection and medical treatments, a diagnosis of breast cancer continues to elicit greater distress on women than any other medical diagnosis, regardless of the prognosis [17]. The nature of this distress can range from psychiatric morbidity, such as depression or anxiety, to post-traumatic stress symptoms $[18,19]$.

Breast cancer patients may experience depression and/ or anxiety at any stage of their illness from pre-diagnosis to the terminal phase of the illness.

It was assumed that the level of psychological distress would be higher around the time of diagnosis. In the current study, the prevalence of anxiety, depression, and perceived stress symptoms in the study group was high (73.3\%, $68.7 \%$, and $78.2 \%$ respectively) and the prevalence of mixed anxiety depression in the study group was $31.25 \%$.

This was consistent with studies of Mehnert and Koch [2] and Burgess et al. [3] which showed that the prevalence of psychological distress among breast cancer patients is high, and they are at higher risk of developing severe anxiety and depression.

The results of the present study were higher than those of Allam et al. [20] who found that anxiety was prevalent in a rate of $15-25 \%$ of the examined cancer breast female patients. Their rates of major depressive disorder were reaching 42.5\%; putting in consideration this smaller sample size (40 cases), the difference could be explained.

Our results were also higher than that of the results of a study conducted by Hassan et al. [21] who found the prevalence of anxiety and depression were $31.7 \%$ and $22.0 \%$ respectively. Also, another study conducted by Vahdaninia et al. [22] who found $38.4 \%$ of their breast cancer patients experienced severe anxiety and $22.2 \%$ had severe depression.

A systematic review of observational studies about prevalence of depression in breast cancer survivors done by Zainal et al. [23] showed that in the Western countries, the prevalence of depression ranges from 1 to $56 \%$, whereas the prevalence of depression from Asian studies was between 12.5 and $31 \%$.

A Turkish study by Dastan and Buzlu [24] reported that $35 \%$ of their breast cancer patients had anxiety, while another Asian study reported a lower prevalence of $16 \%$ [25].

When the severity of depression and anxiety disorders were evaluated, it revealed that most cases were of the moderate to severe form of anxiety (65.6\%) and depression (50\%) respectively. This was consistent with Wellisch et al. [26] who concluded that cancer patients can experience moderate to severe anxiety while waiting for the results of their diagnostic procedures.

In the present study, $31.8 \%$ and $26.2 \%$ of early stage breast cancer patients had depression and anxiety symptoms respectively compared to $68.2 \%$ and $73.8 \%$ of advanced stage breast cancer patients had depression and anxiety symptoms respectively. This was consistent with Moyer and Salovey [27] who found that advanced disease is often considered a risk factor for increased vulnerability to depression and anxiety. Severe psychiatric symptoms are rare among early stage of breast cancer patients (patients with good prognoses), and more common among patients with more advanced stages.

Nevertheless, this was not consistent with other studies like Turner et al. [28] and Li et al. [29] who evaluated 
Table 4 Relationship between the total number of cases and patients with anxiety as regarding patient's and disease's characteristics

\begin{tabular}{|c|c|c|c|c|}
\hline & Total $(\boldsymbol{n}=64)$, no. (\%) & Anxiety $(\boldsymbol{n}=42)$, no. $(\%)$ & Test of significance & $\boldsymbol{p}$ value \\
\hline \multicolumn{5}{|l|}{ Stage } \\
\hline Early & $21(32.8)$ & $11(26.2)$ & $x^{2}=2.43$ & 0.11 \\
\hline Advanced & $43(67.2)$ & $31(73.8)$ & & \\
\hline \multicolumn{5}{|l|}{ Surgery } \\
\hline Done (MRM, CS) & $53(82.8)$ & $34(81.0)$ & $\mathrm{FE}=0.29$ & 0.58 \\
\hline Not & $11(17.2)$ & $8(19.0)$ & & \\
\hline \multicolumn{5}{|l|}{ Marital status } \\
\hline Single & $17(26.5)$ & $12(28.6)$ & $x^{2}=0.25$ & 0.61 \\
\hline Married & $47(73.4)$ & $30(71.4)$ & & \\
\hline \multicolumn{5}{|l|}{ Menopause } \\
\hline Pre & $36(56.3)$ & $21(50.0)$ & $x^{2}=1.93$ & 0.16 \\
\hline Post & $28(43.8)$ & $21(50.0)$ & & \\
\hline \multicolumn{5}{|l|}{ Residence } \\
\hline Urban & $14(21.9)$ & $8(19.0)$ & $x^{2}=0.57$ & 0.45 \\
\hline Rural & $50(78.0$ & $34(81.0)$ & & \\
\hline \multicolumn{5}{|l|}{ Occupation } \\
\hline Unemployed & $61(95.3)$ & $42(100.0)$ & $\mathrm{FE}=6.00$ & $0.03^{\mathrm{a}}$ \\
\hline Employee & $3(4.7)$ & $0(0.0)$ & & \\
\hline \multicolumn{5}{|l|}{ Education } \\
\hline Illiterate & $33(51.6)$ & $19(45.2)$ & $x^{2}=0.50$ & 0.47 \\
\hline Educated & $31(48.4)$ & $23(54.8)$ & & \\
\hline \multicolumn{5}{|l|}{ Income } \\
\hline Satisfactory & 17 (26.6) & $5(29.4)$ & $x^{2}=13.46$ & $<0.001^{\mathrm{a}}$ \\
\hline Not satisfactory & $47(73.4)$ & $37(85.1)$ & & \\
\hline
\end{tabular}

$X^{2}$ chi-squared test, FE Fisher's exact test

asignificant

Australian patients using a structured psychiatric interview (DSM-IV). Among their patients, 303 Australian women with early stage and 227 with advanced breast cancer, the rates of psychiatric morbidity were notably equivalent [30]. This suggests that the stress of the diagnosis was more relevant than stage of disease [30].

In our study, the mean age of the studied group was $52.29 \pm 11.64$ years, ranging from 30.0 to 75.0 years. This was consistent with $\mathrm{Ng}$ et al. [31] who found that majority of patients had age group of 41-60 years followed by age group of $20-40$ years. This finding was also supported by the study conducted by Hassan et al. [21] and The National Cancer Registry 2003 [32], which shows that the commonest age of breast cancer is between 40 and 49 years with mean age of 50 years old.

Most participating women (50.0\%) were illiterate or with basic educational level; they were found to be with the highest prevalence of breast cancer. For the impact of psychiatric morbidity due to the educational level, the prevalence of anxiety and depression was more common in educated women (54.8\%) (56.8\%) respectively as compared to illiterate women (45.2\% and $43.2 \%$ ) respectively. This somehow might be explained by the fact that patients with higher educational levels have a greater opportunity to be aware about their disease and its related aspects. However, a study conducted by Mehnert et al. [20] found that lower educational level has been a predictor of psychological comorbidity in patients with breast cancer.

Married women (73.4\%) were found to have the highest prevalence of breast cancer. For the impact of psychiatric morbidity due to marital status, married woman (71.4\%) showed much higher prevalence of anxiety than single women (28.6\%). Also, married woman (79.5\%) showed much higher prevalence of depression than single women $(20.5 \%)$. In our opinion, married women were more depressed and anxious because they have families to take care of, which is the biggest commitment in their lives. Feel of low self-esteem after having surgery might also contributed to their psychiatric 
Table 5 Relationship between the total number of cases and patients with distress as regarding patient's and disease's characteristics

\begin{tabular}{|c|c|c|c|c|}
\hline & Total $(\boldsymbol{n}=64)$, no. (\%) & Distress $(\boldsymbol{n}=50)$, no. $(\%)$ & Test of significance & $\boldsymbol{p}$ value \\
\hline \multicolumn{5}{|l|}{ Stage } \\
\hline Early & $21(32.8)$ & $18(36.0)$ & $\mathrm{FE}=1.05$ & 0.35 \\
\hline Advanced & $43(67.2)$ & $32(64.0)$ & & \\
\hline \multicolumn{5}{|l|}{ Surgery } \\
\hline Done (MRM, CS) & $53(82.8)$ & $43(86.0)$ & $\mathrm{FE}+1.63$ & 0.20 \\
\hline Not & $11(17.2)$ & $7(14.0)$ & & \\
\hline \multicolumn{5}{|l|}{ Marital status } \\
\hline Single & $17(26.5)$ & $13(26.0)$ & $\mathrm{FE}=0.03$ & 1.00 \\
\hline Married & $4(73.4)$ & $37(74.0)$ & & \\
\hline \multicolumn{5}{|l|}{ Menopause } \\
\hline Pre & $36(56.3)$ & $27(54.0)$ & $x^{2}=0.47$ & 0.49 \\
\hline Post & $28(43.8)$ & $23(46.0)$ & & \\
\hline \multicolumn{5}{|l|}{ Residence } \\
\hline Urban & $14(21.9)$ & $10(20.0)$ & $\mathrm{FE}=0.47$ & 0.48 \\
\hline Rural & $50(78.0$ & $40(80.0)$ & & \\
\hline \multicolumn{5}{|l|}{ Occupation } \\
\hline Unemployed & $61(95.3)$ & $48(96.0)$ & $\mathrm{FE}=0.24$ & 0.62 \\
\hline Employee & $3(4.7)$ & $2(4.0)$ & & \\
\hline \multicolumn{5}{|l|}{ Education } \\
\hline Illiterate & $33(51.6)$ & $25(50.0)$ & $x^{2}=0.22$ & 0.63 \\
\hline Educated & $31(48.4)$ & $25(50.0)$ & & \\
\hline \multicolumn{5}{|l|}{ Income } \\
\hline Satisfactory & $17(26.6)$ & $5(29.4)$ & $\mathrm{FE}=3.94$ & $0.04^{\mathrm{a}}$ \\
\hline Not satisfactory & $47(73.4)$ & $45(95.7)$ & & \\
\hline
\end{tabular}

$X^{2}$ chi-squared test, FE Fisher's exact test

asignificant

morbidity. Since the perception of breast cancer as a fatal disease, they were more worried about their lives and their future. In this study, marital status was not significantly associated with depression or anxiety. This was not consistent with a study conducted by Aass et al. [33] and Hassan et al. [21], which showed that neither the patient's civil status (married, widowed, single) nor their situation of living (living alone or with partner) as significantly related to the prevalence of anxiety and depression.

However, not statistically significant, our study indicated that marital status affects the severity of the psychiatric symptoms whether depressive or anxiety symptoms. Married females were presented with moderate to severe forms of depression as compared to unmarried females. Few studies had examined the effect of marital status. Akechi et al. [34] explained lower rates of the psychological distress found in his sample to the marital status and other factors; married females had lesser psychological distress.
Most of the patients who underwent surgical operation (81.8\%) had depressive symptoms, while $81 \%$ of them had anxiety symptoms with no significant statistical difference than patients who had no surgery.

Other researchers studied the psychological effect of different type of surgical procedures per se. The study conducted by Wellisch et al. [35] revealed that lumpectomy promotes a more intact body image. Another study by Cohen et al. [36] showed that women who had undergone breast-conserving surgery experienced greater levels of psychological distress and worse QoL from 3 years after surgery onward than did the women with mastectomy.

In this study, patients' occupational status was studied to investigate any association between their economic level and psychiatric morbidity. From the findings, most of the patients were not working, $95.3 \%$ and $73.4 \%$ did not have enough income per month. This situation was considered as low living status due to the high living cost in an urban setting. Some of the patients were living 
Table 6 Logistic regression analysis on factors associated with anxiety, depression, and distress among cases

\begin{tabular}{llllll}
\hline Variables & $\mathrm{B}$ & $\begin{array}{l}\boldsymbol{p} \\
\text { value }\end{array}$ & $\mathrm{OR}$ & $95 \% \mathrm{Cl}$ & \\
\cline { 5 - 6 } & & & Lower & Upper \\
\hline Depression & & & & & \\
Stage & 0.143 & 0.802 & 1.154 & 0.378 & 3.524 \\
Surgery & 0.231 & 0.755 & 1.259 & 0.296 & 5.351 \\
Marital status & 0.953 & 0.106 & 2.593 & 0.816 & 8.239 \\
Menopause & 0.223 & 0.684 & 1.250 & 0.427 & 3.657 \\
Residence & 0.163 & 0.807 & 0.850 & 0.231 & 3.128 \\
Occupation & 1.564 & 0.213 & 0.209 & 0.018 & 2.456 \\
Education & 0.680 & 0.215 & 0.507 & 0.173 & 1.485 \\
Income & 0.251 & 0.675 & 0.778 & 0.240 & 2.518 \\
Anxiety & & & & & \\
Stage & 0.854 & 0.123 & 0.426 & 0.144 & 1.260 \\
Surgery & 0.399 & 0.587 & 0.671 & 0.159 & 2.835 \\
Marital status & 0.307 & 0.616 & 1.360 & 0.409 & 4.520 \\
Menopause & 0.762 & 0.167 & 0.467 & 0.158 & 1.377 \\
Residence & 0.466 & 0.452 & 0.627 & 0.186 & 2.112 \\
Occupation & 21.99 & 0.999 & - & - & - \\
Education & 0.373 & 0.480 & 0.688 & 0.244 & 1.940 \\
Income & 0.55 & 0.926 & 0.946 & 0.296 & 3.029 \\
Distress & & & & & \\
Stage & 0.724 & 0.311 & 2.062 & 0.508 & 8.373 \\
Surgery & 0.899 & 0.211 & 2.457 & 0.601 & 10.045 \\
Marital status & 0.130 & 0.847 & 1.138 & 0.304 & 4.26 \\
Menopause & 0.427 & 0.495 & 0.652 & 0.191 & 2.224 \\
Occupation & 0.613 & 0.628 & 1.948 & 0.155 & 21.989 \\
\hline & 0.288 & 0.637 & 0.750 & 0.227 & 2.477 \\
Education & 0.565 & 0.384 & 1.759 & 0.439 & 6.273 \\
\hline
\end{tabular}

in rural areas where the cost of transportation and accommodation can be considerably high. Consequently, majority of the patients claimed that they felt burdened by cancer treatment and its expenses, especially when referring to their economic status.

Depression was more prevalent among the unemployed (97.7\%) and patients who were living in rural areas $(77.3 \%)$ but without statistically significant difference. Anxiety was present among all the unemployed or non-working patients $(100 \%)$ with significant difference than working patients and was present in $81 \%$ of patients who live in rural areas (81\%) but without significant difference with patient living in urban areas. This supported by Ell [37] and Hassan et al. [21], who found that low-income women are characterized by the prevalent of anxiety and depression due to unlikely of receiving any treatments.
In this study, socioeconomic status data were taken from the breast cancer patients to study the relation of economic status towards anxiety and depression. The lower economic status and higher treatment expenses were directly associated with anxiety and depression percentage. Travel to the hospital for treatment needs budget in terms of transportation, fuel, tolls, parking fee, and accommodation. Besides, family or friends who accompany the patient for treatment are not entitled for the hospital meals. Hence, extra expenses are needed to buy for the meals. This supported by Ell [37], who found that major depression disorder (MDD) is prevalent among low-income breast cancer women. It appears to be correlated with pain, anxiety, depression, and healthrelated quality of life. Due to the low economic status, these women are unlikely to receive psychiatry treatment or supportive counseling.

The prevalence of distress in the study group was 78.2\%. This was consistent with $\mathrm{Ng}$ et al. [31] who found that $50 \%$ of the subjects experienced high level of distress. Also, this result was like Burgess et al. [3] who reported that up to $50 \%$ of the women with breast cancer experience high levels of distress with more than $30 \%$ of the women with early breast cancer had depression, anxiety, or both at diagnosis. Also, Zabora et al. [38] and Fallowfield et al. [39] showed that the prevalence of psychological distress in cancer patients is reported to be above $30 \%$.

In this study, Spearman correlation analysis did not show any significant correlation of perceived level of stress with depression $(r 0.22, p 0.07)$ or anxiety $(r 0.09$, $p$ 0.47). This was different from Pandey et al. [40] where distress was found to have positive correlation with anxiety and depression suggesting a possible overlap of the two constructs. However, Ng et al. [31] demonstrated that the perceived level of distress among the breast cancer patients was positively associated with the level of anxiety but not depression.

\section{Limitation of the study}

The use of a small sample, since the study was conducted in a single facility with outpatients, was one of the limiting factors for generalization of the results. Further, longitudinal studies on larger population are needed to ascertain our findings. The generalizability of the samples could be improved in the future by recruiting patients from different settings and regions of the country.

There were some other limitations of the study; the other associated factors for distress were not included in the current study such as pain, financial support, family background, physical suffering, and social support. We only studied the association for the first 12 months after diagnosis. For future analysis, the association between 
distress with anxiety and depression could be studied for later period of the disease and on a longer follow-up further analysis to measure the effect of psychological and lifestyle factors on prognosis of patients. Lastly, the Perceived Stress Scale used in the study was a single item scale. There are other cancer-specific stresses that could not be detected.

\section{Conclusion}

Breast cancer patients experienced high level of distress including depression and anxiety after being diagnosed. Anxiety which could be related to the feeling of uncertainty and depression had no association with the level of perceived distress in this group of patients. With the current findings, more focus on helping breast cancer patients in relieving their feeling of anxiety and depression in the future is important in reducing their perceived level of distress.

\section{Acknowledgements}

The authors thank subjects for their participation and cooperation.

\section{Authors' contributions}

$\mathrm{HA}, \mathrm{SF}, \mathrm{SS}$, and NN analyzed and interpreted the patient data regarding the clinical data and psychometric tools, and MR was a major contributor in writing the manuscript. All authors have read and approved the final manuscript.

\section{Funding}

This study did not receive any fund.

\section{Availability of data and materials}

Not applicable

\section{Ethics approval and consent to participate}

This study was approved by the Ethics Committee of Faculty of Medicine Menoufia University. Written informed consents were obtained from subjects of the study. The number of approvals is not applicable.

\section{Consent for publication}

Not applicable.

\section{Competing interests}

"The authors declare that they have no competing interests" in this section.

\section{Author details}

${ }^{1}$ Department of Clinical Oncology, Faculty of Medicine, Menoufia University, Shibin El Koum, Egypt. ${ }^{2}$ Department of Psychiatry, Faculty of Medicine, Fayoum University, PO Box 63514, Fayoum, Egypt. ${ }^{3}$ Department of Public Health and Community Medicine, Faculty of Medicine, Menoufia University, Shibin El Koum, Egypt. ${ }^{4}$ Department of Family Medicine, Faculty of Medicine, Menoufia University, Shibin El Koum, Egypt.

Received: 13 March 2020 Accepted: 30 April 2020

Published online: 16 July 2020

\section{References}

1. Ferlay J, Soerjomataram I, Ervik M et al (2014) Cancer incidence and mortality worldwide: IARC cancer base no. 11 [Internet]. International Agency for Research on Cancer, Lyon, France

2. Mehnert A, Koch U (2008) Psychological co-morbidity and health-related quality of life and its association with awareness, utilization and need for psychosocial support in a cancer register based sample of long-term breast cancer survivors. J Psychosom Res 64:383-391
3. Burgess C, Cornelius V, Love S, Graham J, Richards M et al (2005) Depression and anxiety in women with early breast cancer: five year observational cohort study. BMJ 330:402-705

4. Ahmet A, Eda U, Umut V et al (2014) Depression, anxiety and sexual satisfaction in breast cancer patients and their partners-izmir oncology group study. Asian Pac J Cancer Pre 15:10631-10636

5. Baumeister H, Kriston L, Bengel J, Härter M (2010) High agreement of selfreport and physician-diagnosed somatic conditions yields limited bias in examining mentalphysical comorbidity. J Clin Epid 63:558-565

6. Härter M, Reuter K, Aschenbrenner A, Schretzmann B, Marschner N et al (2001) Psychiatric disorders and associated factors in cancer: results of an interview study with patients in inpatient, rehabilitation and outpatient treatment. Eur J Cancer 37:1385-1393

7. Maeda T (2008) The effect of psychological intervention on personality change, coping and psychological distress of Japanese primary breast cancer patients. Cancer Nurs 31:27-34

8. Oken MM, Creech RH, Tormey DC et al (1982) Toxicity and response criteria of the Eastern Cooperative Oncology Group. Am. J. Clin. Oncol. 5(6):649-655

9. H Hatata, M Abou Zeid, A Khalil, et al. (2004). Dual diagnosis in substance abuse, a study in an Egyptian sample. MD thesis, Ain Shams University.

10. Beck AT, Ward CH, Mendelson M, Mock J, Erbaugh J (1961) An inventory for measuring depression. Arch Gen Psychiatry 4:561-571

11. Ghareeb A. (2004). Psychometric traits of Beck Depression Inventory-II in the Egyptian environment: part III, (pp. 1850). Cairo: Egyptian Anglo.

12. Spielberger CD, Gorsuch RL, Lushene RE (1983) Manual for the state-trait anxiety inventory. Consulting psychologists press, Palo Alto, CA

13. Abdel-Khalek AM (1989). The devlopment and validation of an Arabic form of the STAI: Egyptian results, Personality and individual differences.vol.10, no3.

14. Cohen S, Kamarck T, Mermelstein R (1983) A global measure of perceived stress. J Health Soc Behav 24:385-396

15. Chaaya M, Osman H, Naassan G, Mahfoud Z (2010) Validation of the Arabic version of the Cohen Perceived Stress Scale (PSS-10) among pregnant and postpartum women. BMC Psychiatry. 10:111. https://doi.org/10.1186/1471244X-10-111

16. SPSS Inc. Released (2015). IBM SPSS statistics for windows, version 23.0, Armnok, NY: IBM Corp.

17. Shapiro SL, Lopez AM, Schwartz GE et al (2001) Quality of life and breast cancer: relationship to psychosocial variables. J Clin Psychol. 57(4):501-519

18. Mehnert A, Koch U (2007) Prevalence of acute and post-traumatic stress disorder and comorbid mental disorders in breast cancer patients during primary cancer care: a prospective study. Psychooncology. 16:181-188

19. Mehnert A, Brähler E, Faller H et al (2014) Four-week prevalence of mental disorders in patients with cancer across major tumor entities. J Clin Oncol. 32:3540-3546

20. Allam M (2003). Psychological profile and quality of life (QoL). Assessment in cancer breast patients. MD thesis: Supervised by Bishry Z., Saad A., Khalifa A. \& Asaad T. Ain Shams University.

21. Hassan MR, Shah SA, Ghazi HF, Mujar NMM, Samsuri MF et al (2015) Anxiety and depression among breast cancer patients in an urban setting in Malaysia. Asian Pac J Cancer Prev 16:4031-4035

22. Vahdaninia M, Omidvari S, Montazeri A (2010) What do predict anxiety and depression in breast cancer patients? A follow-up study. Soc Psychiat Epidemiol 45:355-361

23. Zainal NZ, Nik-Jaafar NR, Baharudin A, Sabki ZA, Ng CG (2013) Prevalence of depression in breast cancer survivors: a systematic review of observational studies. Asian Pac J Cancer Prev 14:2649-2656

24. Dastan NB, Buzlu S (2011) Depression and anxiety levels in early stage Turkish breast cancer patients and related factors. Asian Pacific J Cancer Prev 12:137-14

25. Lueboonthavatchai $P$ (2007) Prevalence and psychosocial 334factors of anxiety and depression in breast cancer patients. J Med Assoc Thai 90:2164

26. Wellisch D, Hoffman A, Goldman S et al (1999) Depression and anxiety symptoms in women at high risk for breast cancer: pilot study of a group intervention. Am J Psychiatry 156:1644-1645

27. Moyer A, Salovey P (1996) Psychosocial sequelae of breast cancer and its treatment. Annals of Behavioral Medicine 18:110-125

28. Turner J, Zapart S, Pedersen K et al (2005) Clinical practice guidelines for the psychosocial care of adults with cancer. Psychooncology. 14(3):159-173

29. Li M, Fitzgerald P, Rodin G (2012) Evidence-based treatment of depression in patients with cancer. J Clin Oncol. 30(11):1187-1196 
30. Kissane DW, Grabsch B, Love A et al. (2004). Psychiatric disorder in women with early stage and advanced breast cancer: a comparative analysis. Aust NZ J Psychiatry.38:320-6.

31. Ng CG, Mohamed S, Kaur K, Sulaiman AH, Zainal NZ, Taib NA et al (2017) Perceived distress and its association with depression and anxiety in breast cancer patients. PLoS ONE 12(3):e0172975

32. NCR (2004). 2nd report of the national cancer registry: cancer incidence in Malaysia 2003. Ministry of health Malaysia.

33. Aass N, Fossa SD, Dahl A, Moe TJ (1997) Prevalence of anxiety and depression in breast cancer patients seen at the Norwegian radium hospital. Eur J Cancer 33:1597-1594

34. Akechi T, Okuyama T, Sugawara Y et al (2004) Major depression, adjustment disorders, and post-traumatic stress disorder in terminally ill cancer patients: associated and predictive factors. J Clin Oncol 22(10):1957-1965

35. Wellisch DK, DiMatteo R, Silverstein M et al (1989) Psychosocial outcomes of breast cancer therapies: lumpectomy versus mastectomy. Psychosomatics 30:365-373

36. Cohen L, Hack TF, de Moor C et al (2000) The effect of type of surgery and time on psychological adjustment in women after breast cancer treatment. Ann Surg Oncol 7(6):427-434

37. Ell K (2005) Depression, correlates of depression and receipt of depression care among low income women with breast cancer or gynecologic cancer. Women Oncol Rev 5:227-228

38. Zabora J, BrintzenhofeSzoc K, Curbow B, Hooker C, Piantadosi S. (2001). The prevalence of psychological distress by cancer site. Psychooncology 10: 1928. pmid:11180574

39. Fallowfield L, Ratcliffe D, Jenkins V, Saul J (2001) Psychiatric morbidity and its recognition by doctors in patients with cancer. Br J Cancer 84:1011e5

40. Pandey M, Sarita GP, Devi N, Thomas BC, Hussain BM et al (2006) Distress, anxiety, and depression in cancer patients undergoing chemotherapy. World J Surg Oncol 4:68

\section{Publisher's Note}

Springer Nature remains neutral with regard to jurisdictional claims in published maps and institutional affiliations.

\section{Submit your manuscript to a SpringerOpen ${ }^{\circ}$ journal and benefit from:}

- Convenient online submission

- Rigorous peer review

- Open access: articles freely available online

- High visibility within the field

- Retaining the copyright to your article

Submit your next manuscript at $\boldsymbol{\nabla}$ springeropen.com 